ASTHMA

\title{
No increase in the prevalence of asthma, allergies, and atopic sensitisation among children in Germany: 1992- 2001
}

\section{K Zöllner, S K Weiland, I Piechotowski, T Gabrio, E von Mutius, B Link, G Pfaff, B Kouros, J Wuthe}

Thorax 2005;60:545-548. doi: 10.1136/thx.2004.029561

See end of article for authors' affiliations

Correspondence to:

Dr I K Zöllner, Department of Epidemiology and Health Reporting, Baden-

Wuerttemberg State Health Office,

Wiederholdstr 15 ,

D-70174 Stuttgart

Germany; Iris.Zoellner@

rps.bwl.de

Received 3 June 2004 Accepted 12 April 2005
Background: From 1970 to 1990 increasing rates of asthma and allergic sensitisation were observed in several countries. The aim of this study was to investigate time trends in the prevalence of asthma and allergic sensitisation among school children in Germany between 1992 and 2001.

Methods: Parental reports of asthma, hay fever, and wheezing and measurements of specific serum lgE antibodies were investigated in six serial cross sectional surveys of 9-11 year old school children in three study areas in south west Germany.

Results: A total of 6762 school children of mean age 10 years (mean participation rate $77.9 \%$ ) took part in the investigation in the three study areas. Over the 9 year study period no increase in the prevalence of current wheezing and asthma was observed. In addition, the prevalence of atopic sensitisation remained unchanged during the observation period.

Conclusions: These data, using parental reports and objective measures of allergy, suggest that there has been no further increase in the prevalence of asthma and atopy since 1992. The epidemic may thus have reached a plateau. lats $\mathrm{n}$ the second half of the last century surveys in many countries showed an increase in the prevalence of asthma and allergies among school children. ${ }^{1-8}$ For example, in Wales the prevalence of a history of asthma had increased from $6 \%$ to $12 \%$ between 1973 and $1988 .^{7}$ Likewise, the prevalence of hay fever in British birth cohorts significantly increased from $12 \%$ in 1974 to $23.3 \%$ in $1986 .{ }^{6}$ This rise has continued until the beginning of this century, as recent data from the UK suggest.' Kuehni and colleagues found an increase in current wheeze in young preschool children from $12 \%$ in 1990 to $26 \%$ in $1998 .^{5}$

Since healthcare costs for asthma pose a heavy burden on society, it is of general interest to know whether this temporal trend is still ongoing or whether a plateau has been reached over the last decade. We therefore aimed to assess the trends in the prevalence of asthma, hay fever, and atopic sensitisation in representative samples of school children living in the south western part of Germany between 1992 and 2001.

\section{METHODS}

\section{Study design}

Cross sectional surveys of 4th grade primary school children were conducted with identical study methods and instruments in three locations in Baden-Wuerttemberg: Mannheim, Kehl and Aulendorf/Bad Waldsee. Mannheim and Kehl are industrialised cities while Aulendorf/Bad Waldsee are more rural. The baseline surveys were conducted between October 1992 and March 1993, and then repeated five times during the same season in 1993/4, 1994/5, 1996/7, 1998/9, and 2000/1. Only children whose parents had given written informed consent participated. The study was coordinated by the Baden-Wuerttemberg State Health Office and approved by the ethics committee of the medical council of Baden-Wuerttemberg. The study sample was defined as all children with available data on sex, age, and residence in the study area for at least 2 years.

\section{Questionnaire}

A comprehensive questionnaire was distributed and filled in by the parents. Data on symptoms of asthma and hay fever were collected using questions from the International Study of Asthma and Allergies in Childhood (ISAAC). ${ }^{10}$ A doctor's diagnosis was defined as an affirmative response to the question: "Has a doctor ever diagnosed one of the following diseases in your child? Asthma (yes/no); Hay fever (yes/no)". In addition to health outcomes, potential confounding factors such as family history of atopy, number of siblings, parental education, breast feeding, and environmental tobacco smoke (ETS) were assessed via the questionnaires. All questions included in the analyses were asked in identical ways during the six surveys.

\section{Serum samples}

From 1992/3 to 1994/5 all school children whose parents gave their written informed consent underwent venous blood sampling. In the following surveys only a random subsample of the children whose parents had completed the questionnaire and given informed consent was invited to participate in the blood sampling for financial reasons. These children were identified during the examination according to a list of IDs which had been selected at random before the start of the field work. The proportion of children participating in the blood sampling among those invited to participate was calculated. A screening test for atopy (SXI, Pharmacia, Uppsala, Sweden) was used to detect specific IgE antibodies against a panel of aeroallergens (mixed grass pollen, birch pollen, mugwort pollen, Dermatophagoides pteronyssinus, cat dander, dog dander, Cladosporium herbarum) in the serum. The laboratory analyses were conducted in a central laboratory in Freiburg and, since 1996, in Stuttgart. Specific sensitisation was defined as a SXI test above the detection limit $(0.35 \mathrm{kU} / \mathrm{l})$. 
Table 1 Characteristics of the study populations

\begin{tabular}{|c|c|c|c|c|c|c|}
\hline & $1992 / 3$ & $1993 / 4$ & $1994 / 5$ & $1996 / 7$ & $1998 / 9$ & $2000 / 1$ \\
\hline Addressed & 1410 & 1309 & 1402 & 1513 & 1500 & 1548 \\
\hline Questionnaires completed & 1077 & 1079 & 1078 & 1171 & 1197 & 1160 \\
\hline Participation rate & $76.4 \%$ & $82.4 \%$ & $76.9 \%$ & $77.3 \%$ & $79.8 \%$ & $74.9 \%$ \\
\hline Study sample* & 919 & 955 & 930 & 1030 & 1036 & 1070 \\
\hline Serum samples & 798 & 763 & 832 & 674 & 722 & 653 \\
\hline Participation in blood samplingt & $86.8 \%$ & $79.9 \%$ & $89.5 \%$ & $78.4 \%$ & $82.4 \%$ & $93.4 \%$ \\
\hline Mean (SD) age (years) & $10.4(0.6)$ & $10.3(0.6)$ & $10.3(0.6)$ & $10.2(0.6)$ & $10.2(0.6)$ & $10.2(0.5)$ \\
\hline Sex (female) & $467(51 \%)$ & $474(50 \%)$ & $450(48 \%)$ & $524(51 \%)$ & $519(50 \%)$ & $503(47 \%)$ \\
\hline German nationality & $761(83 \%)$ & $731(77 \%)$ & $670(72 \%)$ & 717 (70\%) & 739 (71\%) & $772(72 \%)$ \\
\hline \multicolumn{7}{|l|}{ German children only } \\
\hline SES high $\ddagger$ & 145 (19\%) & $196(27 \%)$ & $145(22 \%)$ & $170(24 \%)$ & $194(26 \%)$ & $212(27 \%)$ \\
\hline ETS & $405(53 \%)$ & $360(49 \%)$ & $348(52 \%)$ & $360(50 \%)$ & $366(50 \%)$ & $388(50 \%)$ \\
\hline \multicolumn{7}{|l|}{ No of siblings } \\
\hline$\geqslant 2$ & 297 (39\%) & $264(36 \%)$ & $251(37 \%)$ & $263(37 \%)$ & $278(38 \%)$ & $298(39 \%)$ \\
\hline $\begin{array}{l}\text { Familial history of asthma, atopic } \\
\text { eczema or hay fever }\end{array}$ & $221(29 \%)$ & $243(33 \%)$ & $239(36 \%)$ & $241(34 \%)$ & $269(36 \%)$ & $283(37 \%)$ \\
\hline Breast feeding§ & $158(21 \%)$ & $149(20 \%)$ & $174(26 \%)$ & $220(31 \%)$ & $246(33 \%)$ & $255(33 \%)$ \\
\hline
\end{tabular}

*All children with known sex, age and residence for at least two years in study area.

†Proportion of children participating in blood sampling of those invited to participate (these were random subsamples after 1995)

\#High socioeconomic status (SES) defined as mother, father, or both having at least 13 years of school education.

- Environmental tobacco smoke (ETS) defined as any passive smoke exposure in the home.

$\S$ Exclusive breast feeding for at least 4 months.

\section{Statistical analysis}

Data were checked and analysed in the Baden-Wuerttemberg State Health Office. Until 1994/5 the data were entered manually, and later by scanning techniques. Based on the parental questionnaires and SXI test results, the prevalence of asthma, hay fever and specific IgE was calculated for all six cross sectional surveys. Logistic regression analyses were performed to identify time trends adjusting for potential confounders such as place of residence, sex, family history, parental education, breast feeding, passive smoking, and number of siblings. Time was coded as number of years since the baseline survey. The SAS-PC statistical package (SAS Institute Inc, Cary, NC, USA) was used for computations.

\section{RESULTS}

A total of 8682 school children from three locations were invited to participate. Of the 6762 children with completed parental questionnaires, 796 had not lived in the study area for at least 2 years; 26 children were excluded from the analysis due to missing data. The response rates in the six surveys varied from $74.9 \%$ to $82.4 \%$ and showed no trend over time. Likewise, the sex ratio and mean age remained stable. However, the proportion of children without German nationality increased significantly from $17 \%$ at baseline to $28 \%$ in $2000 / 1$. Since nationality is known to be a strong predictor of atopy in Germany, ${ }^{11}$ all further analyses were conducted stratified by nationality in order to avoid potential confounding. Nationality in Germany reflects ethnicity rather than place of birth. Among German children, a significant increase was seen in the prevalence of children with a family history of atopic disease, of high socioeconomic status, and of those who had been exclusively breast fed for at least 4 months (table 1).

There were no significant changes in the prevalence of symptoms and diagnoses of asthma and hay fever over time (table 2). For example, the prevalence of diagnosed asthma was $4.9 \%, 4.8 \%, 3.0 \%, 4.3 \%, 4.1 \%$, and $5.6 \%$ during the six points in time among German children. In addition, the prevalence of atopic sensitisation remained unchanged during the observation period $(34.1 \%, 29.9 \%, 36.3 \%, 36.4 \%, 35.7 \%$, $34.7 \%$ ). The adjusted odds ratios for changes over time were all very close to 1 and none showed a significant increase. In fact, the adjusted odds ratio for "wheeze ever" showed a significant decrease. None of the factors considered was found to have a substantial influence on the time trends in the multivariate analyses. There was no evidence for differences in time trends by sex, family history of atopy, and presence of atopic sensitisation. The respective prevalence rates among the children without German nationality were generally lower, but no significant changes over time were observed.

\section{DISCUSSION}

Before interpreting the findings, the strengths and limitations of our study have to be addressed. The same

Table 2 Prevalence of asthma and allergies among German children living in three different areas: 1992-2001

\begin{tabular}{|c|c|c|c|c|c|c|c|c|}
\hline & \multirow[b]{2}{*}{$\begin{array}{l}1992 / 3 \\
\text { n (\%) }\end{array}$} & \multirow[b]{2}{*}{$\begin{array}{l}1993 / 4 \\
\text { n (\%) }\end{array}$} & \multirow[b]{2}{*}{$\begin{array}{l}1994 / 5 \\
\text { n (\%) }\end{array}$} & \multirow[b]{2}{*}{$\begin{array}{l}1996 / 7 \\
\text { n (\%) }\end{array}$} & \multirow[b]{2}{*}{$\begin{array}{l}1998 / 9 \\
\text { n }(\%)\end{array}$} & \multirow[b]{2}{*}{$\begin{array}{l}2000 / 1 \\
\text { n (\%) }\end{array}$} & \multicolumn{2}{|l|}{ Time trends } \\
\hline & & & & & & & $\begin{array}{l}\text { Crude OR per year } \\
(95 \% \mathrm{CI})\end{array}$ & $\begin{array}{l}\text { Adjusted }{ }^{*} \text { OR per year } \\
(95 \% \mathrm{CI})\end{array}$ \\
\hline Questionnaire & $N=761$ & $N=731$ & $N=670$ & $N=717$ & $N=739$ & $N=772$ & & \\
\hline \multicolumn{9}{|l|}{ Diagnoses } \\
\hline Asthma & $37(4.9 \%)$ & $35(4.8 \%)$ & $20(3.0 \%)$ & $31(4.3 \%)$ & $30(4.1 \%)$ & $43(5.6 \%)$ & 1.02 (0.97 to 1.07$)$ & $1.00(0.95$ to 1.06$)$ \\
\hline Hay fever & $58(7.6 \%)$ & $47(6.4 \%)$ & $52(7.8 \%)$ & $58(8.1 \%)$ & $62(8.4 \%)$ & $70(9.1 \%)$ & 1.03 (0.995 to 1.07$)$ & 1.02 (0.97 to 1.06$)$ \\
\hline \multicolumn{9}{|l|}{ Symptoms } \\
\hline Wheeze ever & $233(30.6 \%)$ & $228(31.2 \%)$ & $205(30.6 \%)$ & $201(28.0 \%)$ & $205(27.7 \%)$ & $240(31.1 \%)$ & 0.97 (0.94 to 0.99$)$ & 0.95 (0.93 to 0.98$)$ \\
\hline Wheeze in past 12 months & $72(9.5 \%)$ & $80(10.9 \%)$ & $58(8.7 \%)$ & $68(9.5 \%)$ & $73(9.9 \%)$ & $81(10.5 \%)$ & 1.00 (0.97 to 1.03$)$ & $0.99(0.95$ to 1.03$)$ \\
\hline Runny nose/itchy eyes & $70(9.2 \%)$ & $69(9.4 \%)$ & 70 (10.4\%) & $59(8.2 \%)$ & $58(7.8 \%)$ & $79(10.2 \%)$ & 1.00 (0.96 to 1.03 ) & 0.98 (0.94 to 1.02 ) \\
\hline Serum analyses & $N=649$ & $N=606$ & $N=600$ & $N=497$ & $N=552$ & $N=479$ & & \\
\hline Specific lgE (SX1)† & $221(34.1 \%)$ & $181(29.9 \%)$ & $218(36.3 \%)$ & $181(36.4 \%)$ & $197(35.7 \%)$ & $166(34.7 \%)$ & 1.02 (0.99 to 1.04 ) & 0.99 (0.97 to 1.02$)$ \\
\hline
\end{tabular}

*Adjusted for sex, family history of atopic diseases, socioeconomic status, breast feeding, passive smoking, number of siblings, place of living, dampness

†SX1: specific IgE against a panel of aeroallergens (mixed grass pollen, birch pollen, mugwort pollen, Dermatophagoides pteronyssinus, cat dander, dog dander, Cladosporium herbarum). 
standardised study methods and instruments were used in all six surveys. The participation rates remained stable over time. Moreover, all populations were investigated at six different points in time over a span of 9 years. Most other studies assessing temporal changes in the prevalence of asthma and allergies included only two or, at the most, three surveys over time. ${ }^{1-57}$ Additional measurement points give a much more robust estimate of underlying trends. The three locations allowed assessment of consistency across populations which was, in fact, observed. An additional major strength of the study is the fact that objective measurements of allergen specific serum IgE levels were included. It has been argued that trend data which rely exclusively on questionnaire information are subject to reporting bias due to changes in diagnostic habits and perception of disease. ${ }^{12}$ The measurements of serum IgE levels were conducted using a well established and reliable method.

The study areas were selected a priori with regard to air pollution exposure and may not be representative of the whole of Germany. However, the areas of Mannheim and Kehl are comparable to many other industrial areas in Germany, and the rural areas have no specific characteristics limiting the generalisability of the findings. The sample size and length of the observation period was substantial but may have been insufficient to pick up trends in certain subgroups. Although an objective marker of allergy was measured, no pulmonary function testing including airway challenge was performed to support the asthma prevalence estimates. There is, however, no gold standard for a diagnosis of asthma, but previous studies have shown good validity for a physician's diagnosis of asthma. ${ }^{13}$

Numerous studies have reported an increase in the prevalence of asthma and allergies over many decades in the 20th century. Although most studies relied on questionnaire data, the observations have been supported by serial prevalence studies which also used objective measurements of allergy. ${ }^{13}$ While it has been widely accepted that the prevalence of asthma and allergies has increased in the past decades in many western countries, the question arose as to when the epidemic would eventually reach a plateau or start to decrease.

The data presented here show no further increase in the prevalence of symptoms and diagnoses of childhood asthma and allergies between 1992 and 2001. It is important that the prevalence of atopic sensitisation also remained unchanged during the study period. Data on time trends in the prevalence of asthma and atopy in Germany before 1992 are unfortunately not available. It is, however, very likely that increases in the prevalence of asthma and atopy observed before 1992 in many countries also occurred in Germany, and evidence from comparisons between East and West Germany suggests that this occurred particularly among those born after 1960 in the West. ${ }^{14}$ Our findings of no increase since 1992 are in line with reports from Italy. ${ }^{15}$ Ronchetti and colleagues reported an increase in the prevalence of asthma among school children in Rome between 1974 and 1992 but no further increase between 1992 and 1998. While the later period was rather short, it is of interest that other recent studies found similar results. A halt in the increase of prevalence rates during the 1990s was observed in both Swiss and Australian children. ${ }^{16}{ }^{17}$ Both studies also included objective measurements-serum IgE levels in Switzerland and airway responsiveness in Australia-which confirmed the lack of temporal change. Questionnaire based surveys from the UK and China observed decreases in the prevalence of asthma symptoms between the end of the 20th century and the beginning of this century. ${ }^{18}{ }^{19}$ A British study on asthma episodes prompting consultation with general practitioners also observed a downward trend since $1993 .^{20}$
Our findings are therefore in line with those of several others and support the notion that the international epidemic of asthma and allergies may have started to level off during the 1990s, at least in some areas of the western world. ${ }^{21}$ It is not clear which factors are responsible for these changes. Our investigation, like others, ${ }^{15-20}$ did not allow study of the changing trends by specific risk factors. It is possible that a combination of various factors such as nutrition, microbial exposures, early life infections, housing conditions, exposure to outdoor pollutants such as diesel, allergen exposure, and others may have affected the temporal trends..$^{22-29}$

\section{ACKNOWLEDGEMENTS}

The authors thank M Schwenk for very helpful discussions; A FelderKennel, M Schrimpf, and V Maisner for their work in the field investigations; U Weidner, G Korbl, G Horras-Hun, S Broser, E Rzonca, and G Kirsch for their excellent technical assistance; and E Schindler and H Knebel for documenting and preparing the data for analysis.

\section{Authors' affiliations}

I K Zöllner, I Piechotowski, T Gabrio, B Link, G Pfaff, J Wuthe, Baden-

Wuerttemberg State Health Office, Stuttgart, Germany

S K Weiland, Department of Epidemiology, University of Ulm, Ulm, Germany

E von Mutius, Von Haunersches Kinderspital, University of Munich, Munich, Germany

B Kouros, Baden-Wuerttemberg Ministry of Social Affairs, Germany

Competing interests: none declared

\section{REFERENCES}

1 von Mutius E, Weiland SK, Fritzsch C, et al. Increasing prevalence of hay fever and atopy among children in Leipzig, East Germany. Lancet 1998;351:862-6.

2 Rona RJ, Chinn S, Burney PG. Trends in the prevalence of asthma in Scottish and English primary school children 1982-92. Thorax 1995;50:992-3.

3 Peat JK, van den Berg RH, Green WF, et al. Changing prevalence of asthma in Australian children. BMJ 1994;308:1591-6.

4 Ninan TK, Russell G. Respiratory symptoms and atopy in Aberdeen schoolchildren: evidence from two surveys 25 years apart. BMJ 1992;304:873-5.

5 Kuehni C, Davis A, Brooke A, et al. Are all wheezing disorders in very young (preschool) children increasing in prevalence? Lancet 2001;358:1821-5.

6 Butland BK, Strachan DP, Lewis S, et al. Investigation into the increase in hay fever and eczema at age 16 observed between the 1958 and 1970 British birth cohorts. BMJ 1997;315:717-21.

7 Burr M, Butland B, King S, et al. Changes in asthma prevalence: two surveys 15 years apart. Arch Dis Child 1989;64:1452-6.

8 Burney PG, Chinn S, Rona RJ. Has the prevalence of asthma increased in children? Evidence from the national study of health and growth 1973-86. BMJ 1990;300:1306-10.

9 Butland B, Strachan D, Anderson H. The home environment and asthma symptoms in childhood: two population based case-control studies 13 years apart. Thorax 1997;52:618-24.

10 Asher MI, Keil U, Anderson HR, et al. International Study of Asthma and Allergies in Childhood (ISAAC): rationale and methods. Eur Respir $J$ 1995;8:483-91.

11 Kabesch M, Schaal W, Nicolai T, et al. Lower prevalence of asthma and atopy in Turkish children living in Germany. Eur Respir J 1999;13:577-82.

12 Magnus P, Jaakkola J. Secular trend in the occurrence of asthma among children and young adults: critical appraisal of repeated cross sectional surveys. BMJ 1997;314:1795-9.

13 Nicolai T, Mutius EV, Reitmeir P, et al. Reactivity to cold-air hyperventilation in normal and in asthmatic children in a survey of 5,697 schoolchildren in southern Bavaria. Am Rev Respir Dis 1993; 147:565-72.

14 Nicolai T, Bellach B, Mutius EV, et al. Increased prevalence of sensitization against aeroallergens in adults in West compared with East Germany. Clin Exp Allergy 1997;27:886-9.

15 Ronchetti $R$, Villa $M$, Barreto $M$, et al. Is the increase in childhood asthma coming to an end? Findings from three surveys in Rome, Italy. Eur Respir J $2001 ; 17: 881-6$.

16 Toelle B, Ng K, Belousova E, et al. Prevalence of asthma and allergy in schoolchildren in Belmont, Australia: three cross sectional surveys over 20 years. BMJ 2004;328:386-7.

17 Braun-Fahrlander C, Gassner M, Grize L, et al. No further increase in asthma, hay fever and atopic sensitisation in adolescents living in Switzerland. Eur Respir J 2004;23:407-13. 
18 Maziak W, Behrens T, Brasky T, et al. Are asthma and allergies in children and adolescents increasing? Results from ISAAC phase I and phase III surveys in Munster, Germany. Allergy 2003;58:572-9.

19 Anderson HR, Ruggles R, Strachan DP, et al. Trends in prevalence of symptoms of asthma, hay fever, and eczema in 12-14 year olds in the British Isles, 1995-2002: questionnaire survey. BMJ 2004;328:1052-3.

20 Wong GW, Leung TF, Ko FW, et al. Declining asthma prevalence in Hong Kong Chinese schoolchildren. Clin Exp Allergy 2004;34:1550-5.

21 Sunderland RS, Fleming DM. Continuing decline in acute asthma episodes in the community. Arch Dis Child 2004:89:282-5.

22 Nowak D, Suppli Ulrik C, von Mutius E. Asthma and atopy: has peak prevalence been reached? Eur Respir J 2004;23:359-60.

23 Weiland SK, Pearce N. Asthma prevalence in adults: good news? Thorax 2004:59:637-8.
24 von Mutius E. Influences in allergy: epidemiology and the environment. $J$ Allergy Clin Immunol 2004;113:373-9.

25 Bernstein JA, Alexis N, Barnes C, et al. Health effects of air pollution. J Allergy Clin Immunol 2004;114:1116-23.

26 McKeever TM, Britton J. Diet and asthma. Am J Respir Crit Care Med 2004;170:725-9.

27 Eder W, von Mutius E. Hygiene hypothesis and endotoxin: what is the evidence? Curr Opin Allergy Clin Immunol 2004;4:113-7.

28 Custovic A, Simpson A. Environmental allergen exposure, sensitisation and asthma: from whole populations to individuals at risk. Thorax 2004;59:825-7.

29 Upham JW, Holt PG. Environment and development of atopy. Curr Opin Allergy Clin Immunol 2005;5:167-72.

\section{LUNG ALERT}

$\mathrm{PaCO}_{2}$ : a marker of severity in community acquired pneumonia

$\Delta$ Sin DD, Man SFP, Thomas J. Marrie TJ. Arterial carbon dioxide tension on admission as a marker of in-hospital mortality in community-acquired pneumonia. Am J Med 2005;118:145-50

A rterial carbon dioxide tension $\left(\mathrm{PaCO}_{2}\right)$ has not previously been studied in detail as a predictor of mortality in patients with community acquired pneumonia. This retrospective Canadian study examined the relationship between $\mathrm{PaCO}_{2}$ and inhospital mortality in patients with community acquired pneumonia.

Of the 2171 study subjects, in-hospital mortality (10\%) was greater in those with hypocapnia $\left(\mathrm{PaCO}_{2}<32 \mathrm{~mm} \mathrm{Hg}\right)(\mathrm{OR} 1.8(95 \% \mathrm{CI} 1.0$ to 3.2$))$ and hypercapnia $\left(\mathrm{PaCO}_{2}\right.$ $>45 \mathrm{~mm} \mathrm{Hg}$ ) (OR 2.6 (95\% CI 1.5 to 4.5$)$ ) than in those with normal $\mathrm{PaCO}_{2}$ values (40$44 \mathrm{~mm} \mathrm{Hg}$ ). In-hospital mortality rates within these $\mathrm{PaCO}_{2}$ bands were similar for patients with and without chronic obstructive pulmonary disease (COPD). However, COPD was more common in those with hypercapnia and bacteraemia was more common in those with hypocapnia. For patients without bacteraemia, mortality was 2.5 times higher in those with hypercapnia but was not greater in those with hypocapnia, raising the possibility that bacteraemia may be the leading cause of death in hypocapnic patients. Respiratory rate was only loosely correlated with $\mathrm{PaCO}_{2}$ levels and did not increase in-hospital mortality rates. Surprisingly, markers of renal function, blood pressure, age, and respiratory rate did not correlate with mortality rates.

This shows that $\mathrm{PaCO}_{2}$ levels are another marker of in-hospital mortality in community acquired pneumonia and could be used to risk stratify patients on admission. However, the study did not show the mode of death in these patients. Further assessment is required to establish whether $\mathrm{PaCO}_{2}$ levels add value over and above routinely assessed clinical and laboratory parameters.

P Palchaudhuri

Senior House Officer, Department of Infection, Immunity and Thoracic Medicine, Royal Free Hospital, London, UK; paramita03@rediffmail.com 
Table 1 Statistical analysis of the case-control study

\begin{tabular}{|c|c|c|c|c|c|c|c|c|c|c|c|c|}
\hline & \multicolumn{4}{|c|}{ Co-dominant } & \multicolumn{4}{|c|}{ Dominant (AA/AG v GG) } & \multicolumn{4}{|c|}{ Recessive (AA v AG/GG) } \\
\hline & AA & AG & GG & $\begin{array}{l}\mathrm{p} \\
\text { value }\end{array}$ & AA/AG & GG & OR $(95 \% \mathrm{Cl})$ & $\begin{array}{l}\mathrm{P} \\
\text { value }\end{array}$ & AA & GG/AG & OR $(95 \% \mathrm{Cl})$ & $\begin{array}{l}\mathrm{P} \\
\text { value }\end{array}$ \\
\hline Controls & $84(41 \%)$ & $82(41 \%)$ & $36(18 \%)$ & & 166 & 36 & & & 84 & 116 & & \\
\hline Cases & $99(47 \%)$ & $93(44 \%)$ & $18(9 \%)$ & 0.021 & 192 & 18 & 2.31 (1.27 to 4.23$)$ & 0.006 & 99 & 111 & 1.25 (0.85 to 1.85$)$ & 0.276 \\
\hline Acute & $30(42 \%)$ & $32(45 \%)$ & $9(13 \%)$ & 0.576 & 62 & 9 & $1.49(0.68$ to 3.28$)$ & 0.358 & 30 & 41 & $0.99(0.57$ to 1.71$)$ & 0.97 \\
\hline Chronic & 59 (52\%) & $47(41 \%)$ & $8(7 \%)$ & 0.021 & 106 & 8 & 2.87 (1.29 to 6.42$)$ & 0.007 & 59 & 55 & $0.67(0.43$ to 1.07$)$ & 0.095 \\
\hline
\end{tabular}

(95\% CI 1.29 to 6.42), $\mathrm{p}<0.0069$; table 1) with a PAR for AA homozygotes and AG heterozygotes of $50 \%$.

This study underlines the importance of the association of BTNL2 rs2076530 variant with the susceptibility to develop sarcoidosis in a German population. Furthermore, our data suggest that susceptibility is preferentially towards the chronic form of the disease.

Y Li, B Wollnik

Center for Molecular Medicine Cologne (CMMC) and Institute of Human Genetics, University of Cologne,

Germany

S Pabst, M Lennarz

Medizinische Universitäts-Poliklinik, RheinischeFriedrich-Wilhelms Universität Bonn, Germany

E Rohmann

Center for Molecular Medicine Cologne (CMMC) and Institute of Human Genetics, University of Cologne, Germany

A Gillissen

Städtisches Klinikum St Georg, Leipzig, Germany

H Vetter, C Grohé

Medizinische Universitäts-Poliklinik, RheinischeFriedrich-Wilhelms Universität Bonn, Germany

Correspondence to: Professor Dr med C Grohé, Medizinische Universitäts-Poliklinik, Wilhelmstr, 35 37, D-53111 Bonn, Germany; c.grohe@uni-bonn.de

$$
\text { doi: 10.1136/thx.2005.056564 }
$$

Competing interests: none.

\section{References}

1 Newman LS, Rose CS, Maier LA. Sarcoidosis. N Engl J Med 1997;336:1224-34.

2 Rybicki BA, lannuzzi MC, Frederick MM, et al. ACCESS Research Group. Familial aggregation of sarcoidosis. A case-control etiologic study of sarcoidosis (ACCESS). Am J Respir Crit Care Med 2001; 164:2085-91.

3 Valentonyte R, Hampe J, Huse K, et al. Sarcoidosis is associated with a truncating splice site mutation in BTNL2. Nat Genet 2005;37:357-64.

4 Rybicki BA, Walewski JL, Maliarik MJ, et al. ACCESS Research Group. The BTNL2 gene and sarcoidosis susceptibility in African Americans and Whites. Am J Hum Genet 2005;77:491-9.

5 Costabel U, Hunninghake GW. Statement on sarcoidosis. Joint Statement of the American Thoracic Society (ATS), the European Respiratory Society (ERS) and the World Association of

Sarcoidosis and Other Granulomatous Disorders (WASOG) adopted by the ATS Board of Directors and by the ERS Executice Committee. Am J Respir Crit Care Med 1999;160:736-55.

\section{Asthma and allergies in Germany}

We read the study by Zöllner and colleagues published recently in Thorax about the levelling off of asthma and allergies among children in Germany between 1992 and 2001. ${ }^{1}$ We have published a study looking at the same issue and using a similar protocol (ISAAC) $^{2}$ to assess the symptoms, diagnosis, and severity of asthma and allergies in more than 15000 children aged 6-7 and 1314 years between 1995 and 2000 in Münster, Germany. ${ }^{3}$ We found a tendency towards an increase in current symptoms of asthma and allergies in both age groups, but more so among girls. ${ }^{3}$

Indices of diagnosis either remained the same or increased in parallel with the increase in symptoms, arguing against a change in diagnostic behaviour as an explanation for our results. Indices of severity also showed a homogenous increase in the 5 year study period, pointing towards an increase in the overall burden of asthma and allergies within the society. ${ }^{3}$

Regrettably, these results, coming from Germany, were not considered in either the discussion of Zöllner's report or in the affirmative title that no increase in asthma and allergies occurred in Germany in the 1990s. Even more regrettable is the fact that when our study was alluded to in the discussion and conclusion of the paper by Zöllner et al, it was cited-contrary to our results-as one of the studies showing a decrease or levelling off of asthma and allergies among children. ${ }^{1}$

W Maziak, U Keil Institute of Epidemiology and Social Medicine, University Clinic of Muenster, Muenster, Germany; maziak@net.sy

\section{References}

1 Zöllner IK, Weiland SK, Piechotowski I, et al. No increase in the prevalence of asthma, allergies, and atopic sensitisation among children in Germany: 1992-2001. Thorax 2005;60:545-8.

2 Asher MI, Keil U, Anderson HR, et al. International Study of Asthma and Allergies in Childhood (ISAAC): rationale and methods. Eur Respir J 1995;8:483-91.

3 Maziak W, Behrens T, Brasky TM, et al. Are asthma and allergies in children and adolescents increasing? Results from ISAAC phase I and phase III surveys in Münster, Germany. Allergy 2003;58:572-9.

\section{Authors' reply}

Unfortunately, the paper by Maziak et al published in Allergy was listed as reference number 18 instead of number 21 in the reference list of our paper. ${ }^{2}$ We apologise for any misunderstanding which may have arisen from this error. A correction is published below.

In the paper by Maziak et $a l^{1}$ the prevalences in 1994/5 and 1999/2000 are compared. As we know from our own studies, trend analyses based on (only) two time points may be difficult and should be interpreted with caution. Indeed, in their investigation Maziak et al did not find a significant increase in the lifetime prevalence of asthma and hay fever, except in one subgroup. The effect found in 13-14 year old girls could also be due to a former underdiagnosis of asthma in girls, as discussed in their paper.

Since our results are based on six cross sectional surveys, we consider the title and the conclusion-that we did not see an increase in asthma and allergies from 1992 to 2001 - to be appropriate.

I Zöllner

Department of Epidemiology and Health Reporting, Baden-Wuerttemberg State Health Office, Wiederholdstr 15, D-70174 Stuttgart, Germany; Iris.Zoellner@rps.bwl.de

\section{Reference}

1 Maziak W, Behrens T, Brasky TM, et al. Are asthma and allergies in children and adolescents increasing? Results from ISAAC phase I and phase III surveys in Münster, Germany. Allergy 2003;58:572-9

2 Zöllner IK, Weiland SK, Piechotowski, et al. No increase in the prevalence of asthma allergics, and atopic sensitisation among children in

Germany: 1992-2001. Thorax 2005;60:545-8.

\section{CORRECTIONS}

doi: 10.1136/thx.2005.029561 corr 1

In the paper entitled "No increase in the prevalence of asthma, allergies, and atopic sensitisation among children in Germany: 1992-2001" by I K Zöllner et al which appeared in the July 2005 issue of Thorax (2005; 60:545$8)$, the authors apologise for a mistake which occurred in the reference list. Reference number 18 should be number 21 and references 19-21 should be listed as 18-20.

\section{doi: 10.1136/thx.2005.040444corr 1}

The paper entitled "Anticholinergics in the treatment of children and adults with acute asthma: a systematic review with meta-analysis" by G J Rodrigo and J A Castro-Rodriguez (10.1136/thx.2005.040444) has been published previously on 17 June 2005 as a Thorax Online First article but under the incorrect DOI (10.1136/thx.2005.047803). The publishers apologise for this error. The definitive version of the article can be found at the following citation: Thorax 2005;60:740-6.

doi: 10.1136/thx.2005.040881 corr 1

In the paper entitled "Hormone replacement therapy, body mass index and asthma in perimenopausal women: a cross sectional survey" by F Gómez Real et al published in the January 2006 issue of Thorax (2006;61:34-40), the fourth author should be K A Franklin, not K Franklin. 